\title{
Educating Parents to Support Children's Road Safety: A Review of the Literature
}

Dr Sarah E. O’Toole and Dr Nicola Christie ${ }^{1}$

${ }^{1}$ University College London, Centre for Transport Studies, Department for Civil, Environmental and Geomatic Engineering

\section{Corresponding Author}

Correspondence concerning this article should be addressed to Sarah E. O'Toole, University College London, Centre for Transport Studies, Department for Civil, Environmental and Geomatic Engineering, Chadwick Building, 209, Gower St., London, WC1E 6BT. E-mail: s.o’toole@ucl.ac.uk 


\begin{abstract}
This narrative review synthesised the limited work that has been carried out into road safety education targeting parents. Parent education appeared to have a positive impact on child safety seat use and children's bike helmet use, but results regarding the impact of parent education on pedestrian safety were mixed. The review highlighted important gaps in the literature. A key gap being identifying effective ways to engage parents of low socioeconomic and ethnic minority backgrounds. Further, another gap is understanding effective ways to engage and support parents of children with additional needs to build their children's road safety skills. There is some evidence that parent education has a positive impact on these 'at-risk' groups, but little work on how to engage with these groups and the type of parent education required.
\end{abstract}

Key words: Parent education, Road safety, Ethnicity, Deprivation, Children with SEND 


\section{Educating Parents to Support Children's Road Safety: A Review of the Literature}

\section{Scope of the Problem}

Child road safety is a global concern. Road traffic injuries are the second leading cause of death in children 5 to 14 years-old, with children being most likely to be killed as pedestrians and car passengers (Peden et al., 2008). Engaging parents in their children's road safety education will enable children to develop road safety skills through practice in the traffic environment (Muir et al., 2017; Pfeffer \& Tabibi, 2016). However, understanding of the effectiveness of parent education in supporting children's skill development is limited.

\section{Introduction}

Parent road safety education aims to increase knowledge, alter attitudes and change the behaviour of parents in order to ultimately reduce child death and injury on the roads. Educational interventions need to be grounded in evidence and evaluation of their effectiveness needs to be provided (McKenna, 2010). However, currently understanding of parent road safety education is fragmented and hindered by gaps in the literature, particularly in relation to parent education work targeting 'at-risk' groups.

There is a strong link between ethnicity, deprivation and road traffic injury. Black, Asian and Minority Ethnic (BAME) children are at increased risk of road traffic injuries as pedestrians and as car occupants (Christie, 1995; Christie et al., 2010; Thomson, Tolmie, \& Mamoon, 2001). A challenge in understanding the relation between ethnicity and injury risk, however, is differentiating between the effects of ethnicity and socioeconomic status (SES) because BAME groups are typically the most disadvantaged in society (Thomson et al., 2001). Higher 
pedestrian injury rates in deprived areas have been consistently found (Edwards, Green, Lachowycz, Grundy, \& Roberts, 2008; Lyons, Jones, Deacon, \& Heaven, 2003).

Children with additional needs, including physical, sensory and cognitive impairments as well as developmental disorders such as Attention Deficit Hyperactivity Disorder (ADHD) and Autism, may also be at a greater risk in the roads. Resources for typical developing children are often modified for use with children with additional needs (Williams, Savill, \& Wheeler, 2002). However, parents have stated that road safety education often fails to provide the extra assistance needed by children with additional needs and suggested simpler or different resources would benefit some children with learning disabilities (Graham, MacMillan, Murray, \& Reid, 2005).

Despite the increased risk faced by these groups interventions are often being implemented without consideration to the cultural and ethnic beliefs and practices that influence parenting (Bentley et al., 2014). Parents and caregivers do not exist in a vacuum and a one-size-fits-all approach to road safety behaviour change is therefore not effective (Graf et al., 2017). Parenting behaviours differ across cultural and socioeconomic status groups and child needs (Connell \& Prinz, 2002; Hoff, 2013). Road safety education needs to be tailored to meet the needs of different individuals (Assailly, 2017).

The aim of the present review was to examine the evidence-base for parent road safety education in relation to in-car, pedestrian, and cycling safety in order to identify its effectiveness, in terms of both outcomes and process, and to highlight gaps in the literature and avenues for future research. The objectives of this review were: 1) review evidence relating to the effectiveness of parent education, especially those targeting 'at-risk' groups; 2) identify barriers and facilitators to parental engagement; and 3) highlight gaps in the literature in relation 
to understanding of parent road safety education. In this review we use the term parents to encompass those caring for children, whether biological parents or non-biological caregivers.

\section{Method}

A narrative literature review was carried out. In February 2018 a literature search was conducted to identify evaluations of road safety education involving parents for typically developing children, children from low SES and BAME backgrounds, and children with special educational needs and disabilities (SEND). Searches were conducted using Web of Science. Additional searches were made via Medline, EBSCO, Psych and Behavioural Sciences Collection and Science Direct, as well as through secondary data mining of reference lists. Transport grey literature was also searched. The following search terms were used:

a. parent education OR parent intervention OR parent training

b. road safety OR in car safety OR child safety seat use OR pedestrian safety OR cycling safety OR bike safety OR helmet use OR traffic injuries OR child injuries OR road injuries

When searching for literature relating to parent education for children with additional needs the following terms were also included:

c. children with .... additional needs OR special educational needs OR disabilities OR learning disabilities OR ADHD OR autism

The following inclusion criteria was used to determine which papers to include in the review:

1. Interventions targeting children's pedestrian, cycling, and/or in car safety 
2. Interventions targeting children from birth to 16 years-old

3. Interventions that included some parent involvement

4. An evaluation of the intervention

\section{Results}

Review results are presented in two forms: 1) search results and 2) qualitative review.

\subsection{Search Results}

Initial searches resulted in 425 papers. Abstracts were reviewed in accordance with the inclusion criteria, resulting in 34 papers. Following up with references lists led to a further 11 papers being identified. Full articles were then reviewed and 12 papers were excluded, because: six papers did not involve parent education, four papers did not include an evaluation of the initiative, and two papers were not academic articles. This left a final sample of 33 articles. This included 21 articles focusing on in car safety, five articles focusing on pedestrian safety, six articles focusing on cycling safety, and one focusing on multiple aspects of road safety. In the final sample of articles four focused on deprived families, one on BAME families, and one on both low SES and BAME families.

Initial searches resulted in 221 papers relating to children with SEND. Abstracts were then reviewed in line with the inclusion criteria, which resulted in three articles being selected. On review of the full article, two papers were excluded. One paper because it did not focus on parent education and one paper because it was not an academic article. This left one paper for inclusion in the literature review. Table 1 presents the articles selected for inclusion in the current review and briefly describes the intervention.

\subsection{Narrative Review}


The literature surrounding parent road safety education is synthesised and evaluated below.

\subsubsection{In Car Safety}

The majority of evaluations, including a number of randomised control trials, of parent education work have focused on child safety seat use and have been conducted in the United States of America (USA). The effectiveness of child safety seat interventions appeared to vary depending on the type and level of parent involvement.

\subsubsection{Combined Interventions}

A common approach was to embed parent work in broader safety initiatives, but this has been found to have mixed results. For example, while one study found that personalised reports containing tailored advice about child safety seats, smoke alarms and poison storage distributed to parents in hospital emergency departments increased correct safety seat use four to six months post-intervention (Shields et al., 2013), another failed to find an effect two to four weeks post-intervention (Gielen et al., 2007). Similarly, tailored reports distributed in a doctor's waiting room significantly increased parent knowledge about the inappropriateness of young children travelling in the front seat four weeks post-intervention, but greater knowledge of other aspects of safety seats was not observed (McDonald et al., 2005). Providing examples of how parents have used specific safety practices in the reports resulted in greater adoption of car safety behaviours by parents three weeks post-intervention (Nansel et al., 2002). Further, discussing the report with a physician led to greater parent knowledge about safety seats. 
Embedding parent education in school road safety activities has also resulted in mixed findings. Educational leaflets distributed to parents as part of ongoing safety seat work in schools was found to significantly increase seatbelt use (Will \& Dunaway, 2017) and reduce parent endorsement of children using seatbelts only and riding in the front seat (Aitken, Mullins, Lancaster, \& Miller, 2007). Although increases in seat belt use were maintained four months later, there was no effect on the number of children travelling in the back seat following parent education (Will \& Dunaway, 2017). A combined education and enforcement initiative led by the police across two regions in the USA was effective in significantly increasing safety seat use across both sites (Decina, Temple, \& Dorer, 1994). The initiative also increased compliance with safety seat laws, but this was only significant in one area.

\subsubsection{Parent Specific Education}

Fewer initiatives have targeted parents specifically. Four interventions used video media/television adverts highlighting the need for child safety seats (Lewis, Ho, \& Lennon, 2016; Shenoi, Saz, Jones, Ma, \& Yusuf, 2010; Will, Sabo, \& Porter, 2008). An educational DVD for home use led to parents being able to identify significantly more seat use errors than parents who did not view the DVD (Swartz et al., 2013). However, a short 30 second television advert did not significantly influence parent's intentions to check child safety seat restraints (Lewis, Ho, \& Lennon, 2016). Instructional videos may therefore be more effective than media campaigns. Parents were shown the television advert only once, whereas parents who were provided with educational DVDs may have viewed the material more frequently.

Multi-media campaigns involving a range of methods such as radio adverts, leaflets, and educational materials, that have been carried out over a longer period of time have been found to be effective. For example, a booster seat multi-media intervention found that at six weeks post-intervention $98.9 \%$ of parents reported using a booster seat on all trips (Winston, Erkoboni, 
\& Xie, 2007). However, only parent-reported behaviour was assessed and only after the intervention. Though, a multi-media intervention for children from birth to 12 months-old found that parents knowledge of the correct age, weight, and height to transition a child from a rear to forward facing seat or from a forward facing to booster seat and from a booster seat to seatbelt significantly increased six weeks post-intervention (Snowdon, Hussein, PurcStevenson, Follo, \& Ahmed, 2009). Only parent knowledge of the correct height and weight to transition a child from a forward facing seat to a booster seat and from a booster seat to a seat belt was significantly increased one year post-intervention.

Hands-on practical training was particularly effective on seat installation and use significantly improved parent's safety seat knowledge post-training (Muller et al., 2014; Tessier et al., 2017) and reduced observed seat misuse errors (Duchossois, Nance, \& Wiebe, 2008). Being shown how to correctly install a seat by trained technicians increased the likely hood of parents correctly using safety seats four times (Liu et al., 2016). However, nurse provided training lead to a significant increase in seat use errors by new parents (Rogers et al., 2013). But, of the 70 post-intervention mothers $44 \%$ reported receiving no nurse education, $21 \%$ reported receiving a brochure only, and $31 \%$ reported receiving nurse education and not all nurses participating in the study completed the safety seat training. Who is implementing the intervention and the consistency and quality of the intervention may consequently influence its outcomes

\subsection{Pedestrian Safety}

A few studies in the UK and Europe have indirectly targeted parents mostly through traffic clubs. Traffic Clubs providing books designed to involve parents in training their children with progressive exercises lead to a significant increase in the number of parents teaching children about road safety (West, Sammons, \& West, 1993). However, the traffic club did not have a significant effect on the proportion of children who played supervised or unsupervised in the 
streets, who reported crossing the roads with no supervision, or who ran into the road. A video that aimed to teach road safety messages via songs, rhymes and comedy sketches to children did not significantly increase parent's provision of road safety training nor did it influence children's road safety knowledge, even though parents felt it had (Zeedyk \& Wallace, 2003).

School based training involving parents led to an increase in the number of safe routes and a decline in the number of very unsafe routes constructed by children (Thomson et al., 1998). Improvements were robust 40 days later. However, parents were not training their own children. Parent-child activity workbooks, provided as part of school-based road safety initiatives, aiming to increase parent awareness of children's abilities and encourage parents to model safe pedestrian behaviour improved children's pedestrian skills (Rivara, Booth, Bergman, Rogers, \& Weiss, 1991).

More direct parent education on pedestrian safety has included a instructing parents on carrying out a behavioural modification programme with children on the roads (Limbourg \& Gerber, 1981). Children whose parents carried out the behaviour modification programme demonstrated greater pedestrian safety compared to control children four weeks post-intervention. Although reduced, this difference remained at the four-month follow-up. In contrast, a multi-media campaign to encourage parents of children 4 to 11 years-old to be road safety role models showed limited effectiveness and even increased unsafe behaviours by parents, such as crossing the road while on the phone (ChildWise, 2008). This campaign did not educate parents on how to teach their children the desired skills.

\subsection{Cycling Safety}

Cycling safety initiatives have largely involved parents in child focussed programmes. Adding a parent-child homework assignment to a school-based cycling intervention did not improve children's cycling skill or parent attitudes toward cycling post-intervention or five months later 
(Ducheyne, De Bourdeaudhuij, Lenoir, \& Cardon, 2014). In contrast, a classroom cycling intervention that was compared to the same intervention with parental telephone condition, found that both interventions increased helmet use compared to a control group (Hendrickson \& Becker, 1998). Participation of parents was significantly correlated with self-reported helmet use immediately after the intervention and one month later. Combining child and parent education with enforcement initiatives has also been found to be effective in improving helmet use five months post-intervention and two years later (Gilchrist, Schieber, Leadbetter, \& Davidson, 2000). However, the two year follow-up was based on a small subsample of 39 children.

A parent's initiative involving a theoretical session on the development of cycling competencies and a practical session on providing training tips and exercises significantly increased parental assistance in difficult traffic situations, parental intentions to practice cycling with their children, parental self-efficacy regarding their ability to practice cycling with their children, and cycling safety knowledge (Schutzhofer, Luftenegger, Knessl, \& Mogel, 2017). Children of parents who attended the training also performed significantly better on a practical cycling safety test reflecting a complex traffic situation. Targeted parent education may consequently have a positive impact on parent and child cycling behaviour.

\section{Ethnicity, Deprivation and Parent Road Safety Education}

Evidence suggests road safety education targeting BAME or low SES parents has a positive impact on parent and child behaviour. Kerbcraft was developed to improve the pedestrian skills of 5 to 7 year-olds living in deprived areas (Thomson, 2008) and significantly improved children's road safety skills (Whelan, Towner, Errington, \& Powell, 2008). Parent involvement, however, was an auxiliary aim of this initiative. Intervention effectiveness varied with deprivation levels. A school-based bike safety initiative that included parent information letters 
and nights was found to increase helmet to use to a much greater extent in high-income regions compared to low-income regions in Canada (Parkin et al., 1993). In contrast, a school-based intervention targeting helmet use of 9 to 10 year-olds from low-income, rural communities was found to have a positive impact (Hendrickson \& Becker, 1998). In one condition, telephone calls to parents encouraged parental reinforcement of the bike safety information their children received at school. Parent involvement was significantly correlated with self-reported helmet use immediately after the intervention and one month later.

Partnering with organisations working with deprived families may increase intervention success. For example, a multifaceted programme carried out via Head Start (an organisation working to improve outcomes for children from low SES families) targeting low income parents was effective in promoting helmet use (Britt, Silver, \& Rivara, 1998). Further, a safety seat intervention that was carried out in conjunction with childcare centres for children 4 to 8 yearsold increased booster seat use for 4 to 6 year-olds, but not 7 to 8 year-olds, indicating that the developmental stage of the child may influence intervention effectiveness (Apsler, Formica, Rosenthal, \& Robinson, 2003). An evaluation of a range of interventions targeting parents of children 3 to 7 years-old with low educational backgrounds revealed that parents were motivated by concrete messages that reinforced injury prevention benefits of booster seats provided in video programmes (Winston et al., 2007).

Limited attention has been directed toward assessing the impact of parent education on road safety in BAME groups. Different approaches may be needed for deprived and BAME families. A community booster seat initiative involving a fitting station, media and public services announcements, community education, and booster seat workshops did not increase booster seat use for 4 to 8 year-olds in low income communities (St Louis et al., 2008). However, when this initiative was combined with education events as local churches and a public blessing of the booster seats at a local church, booster seat use did significantly increase in the Hispanic 
community. A community intervention targeting American Indian and Alaska Native families, over a three year period resulted in children being three times more likely to be observed in safety seats (Letourneau, Crump, Bowling, Kuklinski, \& Allen, 2008). This increase, though, was not fully sustained in subsequent years.

\section{Road Safety Education for Parent of Children with Additional Needs}

Limited attention has been paid to the evaluation of road safety education for parents of children with additional needs. A case study of Kerbcraft found it to be effective with children with additional needs due to its practical and interactive nature (Graham et al., 2005). Road safety knowledge and pedestrian skill were significantly greater for 10 to 16 year-olds with learning disabilities that participated in carer-led training compared to service-provider-led training (Phillips \& Todman, 1999). Limited information was provided on the nature of this training.

\section{Discussion}

Although the importance of involving parents in children's road safety education is often highlighted (Muir et al., 2017), there has been limited evaluation of its effectiveness. Evidence indicated that child safety seat education improved parent's knowledge of correct safety seat installation (Swartz et al., 2013), increased safety seat use (Liu, Yang, Cheng, \& Li, 2016), and reduced seat misuse errors (Duchossois et al., 2008). In contrast, much less attention has been paid to the evaluation of parent education regarding pedestrian and cycling safety. The limited studies conducted suggested that parent education has a positive impact on children's cycling safety (Schutzhofer et al., 2017) and helmet use (Britt et al., 1998; Parkin et al., 1993). Although some evidence indicated that parent education improved children's pedestrian behaviour (Limbourg \& Gerber, 1981), other studies have found that increased parent training does not necessarily translate to better road safety knowledge in children (West et al., 1993). Initiatives that specifically target parents and provide hands-on training (Liu et al., 2016), educate parents 
on how to teach children (Nansel et al., 2002), and that are grounded in behavioural theory (Limbourg \& Gerber, 1981) are particularly effective.

\subsection{Gaps in the literature}

The majority of road safety initiatives have included parent education as one aspect of a broader programme. For example, parent education is often combined with child education on road safety (Will \& Dunaway, 2017), enforcement initiatives (Gilchrist et al., 2000), or provided as part of a broader safety campaign (Shields et al., 2013). Not only is there mixed results regarding the effectiveness of this approach, but the multifaceted nature of these approaches means that the independent impact of parent education on child road safety cannot be isolated. Added to this, future research needs to compare the effectiveness of parent education against other approaches.

There is great variation in what constitutes parent education. Road safety programmes involve parents to varying levels and use a variety of approaches: workshops, information leaflets and videos, homework activities, books, and media campaigns (ChildWise, 2008; Schützhofer et al., 2017; Swartz et al., 2013; West et al., 1993). Further evaluation of the most effective means of providing educational information to parents needs to be undertaken. The relation between intervention and behaviour change needs to be understood. Parent education does not always translate to improved road safety skills in children (West et al., 1993).

Varying methods to assess intervention effectiveness have been used. Observations have been frequently used (e.g. Decina et al., 1994), but the extent to which those observed were exposed to the initiative is not known. More direct assessments, including observations of parents who 
were exposed to the intervention (e.g. Tessier, 2010) or parent self-report questionnaires (e.g. West et al., 1993) may more accurately capture changes resulting from intervention. It should be borne in mind, though, that parent reported behaviours may not always reflect actual behaviour. Future evaluations should therefore be focused on assessing both parent and child outcomes following participation in the intervention. The majority of studies focussed on short term outcomes, typically one to six months post-intervention. There is support for the shortterm effectiveness of parent education, but these improvements may not be evident after a longer period of time.

Little research has been carried out on how best to involve parents' i.e process evaluation. Understanding challenges surrounding recruitment will enable programmes to more effectively engage with parents. An evaluation of a child safety seat initiative, for example, found that the incentive of a free booster seat was not sufficient for many parents and as a result free food vouchers, flyers, and high backed booster seats suitable for installation in older vehicles were used (Apsler et al., 2003). Participation rates, though, were only around 50\%. Exploring the consistency and quality of training may provide context for understanding intervention outcomes. For instance, the finding that nurse led training increased safety seat use errors may reflect the fact only $20 \%$ of nurses attend the training (Rogers et al., 2013). Effectiveness of interventions may also be better understood when parental engagement is considered. Indeed, low parental engagement with traffic club books may explain their limited influence on parent knowledge and behaviour (West et al., 1993).

There has been limited research exploring road safety education for parents of 'at-risk' groups, particularly in relation to children with additional needs. Traditional road safety approaches may not be effective with parents from low SES or BAME backgrounds or who have children with SEND (e.g. St Louis et al., 2008). Further research is therefore needed to identify 
facilitators and barriers to engaging with these groups. This is an important area of work as it will enable effective initiatives to be developed that target the most vulnerable in society.

\subsection{Limitations}

The present review provides a narrative account of road safety initiatives that aim to encourage parents to educate their children about road safety. It is important to note that evaluations of interventions that involved parents more indirectly (e.g. parent-child homework) may have been missed when searching for papers. The current review is also limited by the quality of the evaluations that have been included in the review. Although there were substantial randomised control trials, evaluations varied in their quality.

\subsection{Conclusions}

The following conclusions regarding the role of parent education on road safety were drawn:

i. Parent education on road safety can have positive impacts on both parent and child behaviour and knowledge, including: child safety seat use, knowledge of correct installation of child safety seats, child and adult pedestrian skills, parental and child cycling behaviour, and helmet use in children.

ii. Across all areas of road safety, interventions that targeted parents more directly and provided more hands-on training for parents were more effective in improving parent knowledge and behaviour.

iii. Multifaceted initiatives that engage with organisations already working with 'at-risk' communities have been found to increase booster seat use and helmet us in children from deprived backgrounds. 


\section{Acknowledgements}

This research was supported by a grant from the Road Safety Trust.

\section{Declaration of Interest Statement}

The authors declare that they have no conflict of interests. 


\section{References}

Aitken, M. E., Mullins, S. H., Lancaster, V. E., \& Miller, B. K. (2007). "Cubs Click It for Safety": A school-based intervention for tween passenger safety. Journal of TraumaInjury Infection and Critical Care, 63, S39-S43. doi:10.1097/TA.0b013e31812f5ef4

Alexander, K., Bartley, H., \& Davern, T. (2017). Child Road Safety (17/01). Australia: RACV.

Apsler, R., Formica, S. W., Rosenthal, A. F., \& Robinson, K. (2003). Increases in booster seat use among children of low income families and variation with age. Injury Prevention, 9, 322 - 325. doi:10.1136/ip.9.4.322

Assailly, J. P. (2017). Road safety education: What works? Patient Education Counselling, 100, S24-S29. doi:10.1016/j.pec.2015.10.017

Bentley, M. E., Johnson, S. L., Wasser, H., Creed-Kanashiro, H., Shroff, M., Fernandez Rao, S., \& Cunningham, M. (2014). Formative research methods for designing culturally appropriate, integrated child nutrition and development interventions: An overview. Annals of the New York Academy of Science, 1308, 54-67. doi:10.1111/nyas.12290

Britt, J., Silver, I., \& Rivara, F. P. (1998). Bicycle helmet promotion among low income preschool children. Injury Prevention, 4, 280-283. doi:10.1136/ip.4.4.280

ChildWise. (2008). Parents Road Safety Advertising Tracking (10.08). London, UK: Department for Transport. 
Christie, N. (1995). The high risk child pedestrian- socio-economic and environmental factors in their accidents. Transport Research Laboratory.

Christie, N., Ward, H., Kimberlee, R., Lyons, R., Towner, E., Hayes, M., . . Brussoni, M. (2010). Road Traffic Injury Risk in Disadvantaged Communities: Evaluation of the Neighbourhood Road Safety Initiative (19). London, UK: Department for Transport

Connell, C. M., \& Prinz, R. J. (2002). The impact of childcare and parent-child interactions on school readiness and social skills development for low-income African American Children. Journal of School Psychology, 40, 177 - 193. doi:10.1016/s00224405(02)00090-0

Decina, L. E., Temple, M. G., \& Dorer, H. S. (1994). Increasing child safety seat use and proper use among toddlers: Evaluation of an enforcement and education program. Accident Analysis and Prevention, 26, 667 - 663. doi:10.1016/0001-4575(94)90028-0

Ducheyne, F., De Bourdeaudhuij, I., Lenoir, M., \& Cardon, G. (2014). Effects of a cycle training course on children's cycling skills and levels of cycling to school. Accident Analysis and Prevention, 67, 49-60. doi:10.1016/j.aap.2014.01.023

Duchossois, G. P., Nance, M. L., \& Wiebe, D. J. (2008). Evaluation of child safety seat checkpoint events. ccident Analysis and Prevention, 40, 1908-1912. doi:10.1016/j.aap.2008.08.003

Edwards, P., Green, J., Lachowycz, K., Grundy, C., \& Roberts, I. (2008). Serious injuries in children: Variation by area deprivation and settlement type. Archieves of Disease in Childhood, 93, 485-489. doi:10.1136/adc.2007.116541

Gielen, A. C., McKenzie, L. B., McDonald, E. M., Shields, W. C., Wang, M. C., Cheng, Y. J., ... Walker, A. R. (2007). Using a computer kiosk to promote child safety: Results of a randomized controlled trial in an urban pediatric emergency department. Pediatrics, 120, 330-339. doi:10.1542/peds.2006-2703 
Gilchrist, J., Schieber, R. A., Leadbetter, S., \& Davidson, S. C. (2000). Police enforcement as part of a comprehensive bicycle helmet program. Pediatrics, 106, 6-9. doi:10.1542/peds.106.1.6

Graf, E., Garofalo, L., Hundertmark, A. C., Montague, G. L., Polash, N. M., Suskin, E., .. . Suskind, D. L. (2017). Using formative research to develop a hospital-based perinatal public health intervention in the United States: The Thirty Million Words Initiative Newborn Parent Education Curriculum. Journal of Early Hearing Detection and Intervention, 2, 2-11.

Graham, T., MacMillan, K., Murray, A., \& Reid, S. (2005). Improving Road Safety Education for Children with Additional Support Needs. Scotland, UK.

Hendrickson, S. G., \& Becker, H. (1998). Impact of a theory based intervention to increase bicycle helmet use in low income children. Injury Prevention, 4, 126-131. doi:10.1136/ip.4.2.126

Hoff, E. (2013). Interpreting the early language trajectories of children from low-SES and language minority homes: Implications for closing achievement gaps. Developmental Psychology, 49, 4-14. doi:10.1037/a0027238

Letourneau, R. J., Crump, C. E., Bowling, J. M., Kuklinski, D. M., \& Allen, C. W. (2008). Ride Safe: A child passenger safety program for American Indian/Alaska Native children. Maternal and Child Health Journal, 12, S55-S63. doi:10.1007/s10995-0080332-6

Lewis, I., Ho, B., \& Lennon, A. (2016). Designing and evaluating a persuasive child restraint television commercial. Traffic Injury Prevention, 17, 271-277.

doi:10.1080/15389588.2015.1072626 
Limbourg, M., \& Gerber, D. (1981). A parent training program for the road safety education of preschool children. Accident Analysis and Prevention, 13, 255-267. doi:10.1016/0001-4575(81)90008-7

Liu, X., Yang, J., Cheng, F., \& Li, L. (2016). Newborn parent based intervention to increase child safety seat use. International Journal of Environmental Research and Public Health, 13, 1-10. doi:10.3390/ijerph13080777

Lyons, R. A., Jones, S. J., Deacon, T., \& Heaven, M. (2003). Socioeconomic variation in injury in children and older people: a population based study. Injury Prevention, 9, 33 - 37. doi:10.1136/ip.9.1.33

McDonald, E. M., Solomon, B., Shields, W., Serwint, J. R., Jacobsen, H., Weaver, N. L., . . . Gielen, A. C. (2005). Evaluation of kiosk-based tailoring to promote household safety behaviors in an urban pediatric primary care practice. Patient Education and Counseling, 58, 168-181. doi:10.1016/j.pec.2004.08.015

McKenna, F. (2010). Education in road safety: Are we getting it right? (10/113). Retrieved from London:

Muir, C., O'Hern, S., Oxley, J., Devlin, A., Koppel, S., \& Charlton, J. L. (2017). Parental role in children's road safety experiences. Transportation Research Part F: Traffic Psychology and Behaviour, 46, 195-204. doi:10.1016/j.trf.2017.01.014

Nansel, T. R., Weaver, N., Donlin, M., Jacobsen, H., Kreuter, M. W., \& Simons-Morton, B. (2002). Baby, be safe: the effect of tailored communications for pediatric injury prevention provided in a primary care setting. Patient Education and Counseling, 46(3), 175-190. doi:10.1016/s0738-3991(01)00211-7

Parkin, P. C., Spence, L. J., Hu, X., Kranz, K. E., Shortt, L. G., \& Wesson, D. E. (1993). Evaluation of a promotional strategy to increase bicycle helmet use by children. Pediatrics, 91, 772-777. 
Peden, M., Oyegbite, K., Ozanne-Smith, J., Hyder, A. A., Branche, C., Rahman, A. F., . . Bartolomeos, K. (2008). World Report on Child Injury Prevention. Switzerland: World Health Organisation

Pfeffer, K., \& Tabibi, Z. (2016). British parents' self-reported road safety beliefs, practices, and rules. Paper presented at Injury Prevention Conference.

Phillips, S., \& Todman, J. (1999). Pedestrian skills training for children with learning dificulties. International Journal of Rehabilitation Research, 22, 237-238. doi:10.1097/00004356-199909000-00011

Rivara, F. P., Booth, C. L., Bergman, A. B., Rogers, L. W., \& Weiss, J. (1991). Prevention of pedestrian injuries to children: Effectiveness of a school training program. Pediatrics, $88,770-775$.

Rogers, S. C., Gallo, K., Saleheen, H., \& Lapidus, G. (2013). Can nurse education in the postpartum period reduce car seat misuse among newborns? Journal of Trauma Acute Care Surgery, 75, S319-323. doi:10.1097/TA.0b013e31829cba75

Schutzhofer, B., Luftenegger, M., Knessl, G., \& Mogel, B. (2017). Evaluation of the FASIKI traffic safety programme for parents of cycling children. Transportation Research Part F-Traffic Psychology and Behaviour, 46, 500-508. doi:10.1016/j.trf.2016.08.004

Shields, W. C., McDonald, E. M., McKenzie, L., Wang, M. C., Walker, A. R., \& Gielen, A. C. (2013). Using the pediatric emergency department to deliver tailored safety messages results of a randomized controlled trial. Pediatric Emergency Care, 29, 628634. doi:10.1097/PEC.0b013e31828e9cd2

Snowdon, A. W., Hussein, A., Purc-Stevenson, R., Follo, G., \& Ahmed, E. (2009). A longitudinal study of the effectiveness of a multi-media intervention on parents' knowledge and use of vehicle safety systems for children. Accident Analysis and Prevention, 41, 498-505. doi:10.1016/j.aap.2009.01.013 
St Louis, R. M., Parow, J. E., Eby, D. W., Bingham, C. R., Hockanson, H. M., \& Greenspan, A. I. (2008). Evaluation of community-based programs to increase booster seat use. Accident Analysis and Prevention, 40, 295-302. doi:10.1016/j.aap.2007.06.004

Steinbach, R., Green, J., Edwards, P., \& Grundy, C. (2010). 'Race' or place? Explaining ethnic variations in childhood pedestrian injury rates in London. Health Place, 16, 34-42. doi:10.1016/j.healthplace.2009.08.002

Swartz, L., Glang, A., Schwebel, D. C., GeigerWolfe, E. G., Gau, J., \& Schroeder, S. (2013). Keeping baby safe: A randomized trial of a parent training program for infant and toddler motor vehicle injury prevention. Accident Analysis and Prevention, 60, 35-41. doi:10.1016/j.aap.2013.07.026

Tessier, K. (2010). Effectiveness of hands-on education for correct child restraint use by parents. Accident Analysis and Prevention, 42, 1041-1047. doi:10.1016/j.aap.2009.12.011

Thomson, J. A. (2008). Kerbcraft Training Manual: A Handbook for Road Safety Professionals. London, UK: Department for Transport.

Thomson, J. A., Ampofo-Boateng, K., Lee, D. N., Grieve, R., Pitcairn, T. K., \& Demetre, J. D. (1998). The effectiveness of parents in promoting the development of road crossing skills in young children. British Journal of Educational Psychology, 68, 475-491. doi:10.1111/j.2044-8279.1998.tb01306.x

Thomson, J. A., Tolmie, A. K., \& Mamoon, T. P. (2001). Road Accident Involvement of Children from Ethnic Minorities. Road Safety Research Report, 19. ISSN 1468-9138

West, R., Sammons, P., \& West, A. (1993). Effects of a traffic club on road safety knowledge and self-reported behaviour of young children and their parents. Accident Analysis and Prevention, 25, 609-618. doi:10.1016/0001-4575(93)90012-1 
Whelan, K., Towner, E., Errington, G., \& Powell, J. (2008). Evaluation of the National Child Pedestrian Training Pilot Projects (82). London, UK: Department for Transport.

Will, K. E., \& Dunaway, K. E. (2017). Evaluation of a participative education process for increasing tween restraint use in Virginia: The Make it Click initiative. Transportation Research Part F: Traffic Psychology and Behaviour, 45, 54-64. doi:10.1016/j.trf.2016.11.013

Williams, K., Savill, T., \& Wheeler, A. (2002). Review of the road safety of disabled children and adults (TRL559). London, UK: Transport Research Laboratory

Winston, F. K., Erkoboni, D., \& Xie, D. (2007). Identifying interventions that promote bellpositioning booster seat use for parents with low educational attainment. Journal of Trauma-Injury Infection and Critical Care, 63, S29-S38. doi:10.1097/TA.0b013e318126ebb

Zeedyk, M. S., \& Wallace, L. (2003). Tackling children's road safety through edutainment: An evaluation of effectiveness. Health Education Research, 18, 493-505. doi:10.1093/her/cyf033 
1 Table 1. Summary of interventions and results of studies included in review

Study Participants Intervention

Findings

Child Safety Seat Use

Aitken et al. 473 families

5-month school intervention with

Decline in parent endorsement of

(2007)

educational parent brochures on

seatbelt use only ( $37 \%$ to $25 \% * *)$ and

USA

in car-safety.

riding in the front $(10 \%$ to $5 \% *)$ for 5 -

8 year-olds.

Apsler et al. 185 pre- and $147 \quad$ Parent, staff, and child education

Increase in booster seat use for 4-5

(2003)

post-intervention

and policy intervention at

year-olds (5\% vs. $63 \% * *)$ and 6 year-

USA

low income

childcare centres on seat use.

olds (2\% vs. $19 \% * *)$, but not $7-8$ year-

caregivers with 4-8

olds.

year-olds

Decina et al., 4,562 drivers with

12-month parent education and

Safety seat use increased (60.9\% -

(1994)

5,859 child

police enforcement intervention

$71.8 \% *$ vs. $71.4 \%-76.8 \% *)$ and

USA

passengers $(1-5 \quad$ on seat use.

compliance with seat laws improved

years-old)

(80.1\%-90.1\% vs. $90 \%-92 \% *)$.

Duchossois

160 pre- and 42

Parent education at car seat

Observations of at least one seat error

et al., (2008) post-intervention

checkpoint on correct seat fitting.

reduced for the 17 children in rear

facing seats (100\% vs. $18.8 \% * * *)$ and

USA

caregivers with 1

the 25 children in rear facing seats

olds.

$(100 \%$ vs. $64 \% * * *)$. 
Gielen et al. 759 caregivers of 4- Personalised report containing (2007)

USA

Shields et al. 720 parents of 4

USA

Letourneau

3,500 American

36-month teacher, health

et al. (2008)

USA

Lewis et al. $\quad 384$ parents

Australia

Liu et al.,

(2016)

China

McDonald et 144 parents of 6

al. (2005)

USA

olds

Muller et al. 491 caregivers

USA passenger safety. restraints. seat on correct seat fitting.

Personalised report containing passenger safety. on seat use. tailored safety messages on child

Intervention parents more likely to report correct safety seat use 4-6 months post-intervention (OR: 1.36*).

Children three times more likely to be observed in safety seats postintervention.

No significant effect on intentions to advertisement on checking child self-check child restraints.

Parent education and free safety use ( $22.6 \%$ use, $40.5 \% * * *$ non-use) and parent knowledge.

Increased parent knowledge of tailored safety messages on child inappropriateness of young children travelling in front seat postintervention ( $16 \%$ vs. $5 \% *)$. Improved parent knowledge of safety education session for 10 months seats. 
Nansel et al.

(2002)

USA

Rogers et al.

USA

Shenoi et al.

(2010)

USA

Snowdon et

al. (2009) month-olds

Canada

St. Louis et

al. (2008)

USA
213 parents of $6-20$ month-olds

60 pre- and 70 postintervention

Maternal-newborn

dyads

244 parents of children under 9 years-old
Personalised report containing tailored safety messages on child passenger safety

Nurse education to encourage nurses to provide hands-on parent training.

Parent education video on child passenger safety.
Risk score decreased for parents postintervention.

Observed seat misuses increased postintervention (1.8 vs $\left.3.0^{*}\right)$.

Parent knowledge increased postintervention (4.95 vs. $5.24 *)$.
Parent's knowledge of when to transition a child to the next seat improved post-intervention, but reduced one year-later. in vehicles.

Community education intervention to encourage booster seat use.

focussed on: correct safety seat use; seat transitioning times; risk and injury outcomes for children$$
\text { reduced one year-later. }
$$

Booster seat use increased in the

Hispanic community (9.7\% vs. $14.9 \% *)$, but not in the low-income community (19\% vs. $16.9 \%)$

\section{4 low income}

parents of 4-8 year-

olds and 165

Hispanic parents 
Swartz et al. 195 parents of 0-24 Parent education DVD on seat

(2013)

USA

Tessier

(2010)

USA

Will et al. Study 1: 226

(2008)

USA

Dunaway

(2016)

USA

Winston et 171 parents with

al. (2007)

USA

month-olds

use.

months) parents hands on fitting session.

caregivers

Study 2: 3382

observations

762 participants

with 8-12 year-olds leaflets.

8 year-old children.
111 expecting ( $>7-\quad$ Parent education on seat use and

School intervention with parent

6 min parent video about booster

seat and rear seat use among 4 to

seat use intentions increased.

Seatbelt use increased post-

intervention $(31.9 \%$ vs. $56.2 \% * * *)$

and 4 months later $(67.9 \% * * *)$.
Range of interventions to promote Video alone increased intention to use

booster seat use, including: radio booster seats 6 weeks post-

campaigns, educational videos, intervention.

3-7 year-olds and educational materials. 


$\begin{array}{llll}\text { Limbourg \& } & \text { 658 3-6 years-olds } & \text { 30 minute film and instruction } & \text { Children showed better pedestrian } \\ \text { Gerber } & \text { and their parents. } & \text { booklet on teaching children } & \text { safety post-intervention and at } 4 \\ \text { (1981) } & & \text { pedestrian safety. } & \text { month follow-up. }\end{array}$

Germany

Rivara et al. 137 5-10 year-olds 8 session child-focussed

1989: Intervention increased children in 1989 and 92 in

intervention including parent-

keeping looking while crossing.

USA 1990

child activity workbooks to

encourage parents to model safe

1990: Intervention increased overall pedestrian skills.

pedestrian behaviour.

Thomson et 605 year-olds

Parent volunteers assisted in

Number of safe routes constructed

al. (1998)

training children on safe places to

increased (15\% vs. $43 \% *)$ and number

UK cross.

of very unsafe routes declined (43\% vs

$8 \% *)$. Improvements were robust 40

days later.

West et al., 1032 parents with 3 Books encouraging parents to

Increase in number of parents teaching

year-olds pre- and

train their children in pedestrian

children about road safety $(73-77 \%$

UK 1601 parents post- skills.

vs. $79-76 \% *)$, but no significant

intervention

effect on children's pedestrian

behaviour.

Zeedyk \&

120 families with 5

67 min video to teach road safety

No significant effect on parent's

Wallace year-olds

via songs, rhymes and comedy

provision of road safety training.

sketches to children.

UK

Cycling Safety 


$\begin{array}{llll}\text { Britt et al. } & 8803-4 \text { years- } & \text { Parent education on benefits and } & \text { Increase in reported helmet ownership } \\ (1998) & \text { olds } & \text { use of bicycle helmets as well as } & \text { and use from } 43 \% \text { to } 89 \% * \text { post- } \\ \text { USA } & & \text { classroom instruction, helmet } & \text { intervention. } \\ & & \text { fittings, and bicycle rodeos. }\end{array}$

Ducheyne et $\quad 117$ 9-10 year-olds 45 min practical cycling sessions Children's cycling skill improved

al. (2014) plus parent-child homework post-intervention and 5 months later.

Belgium assignments.

Gilchrist et 580 5-12 year-olds Parent education and police

Helmet use of the 358 children

al. (2000)

enforcement intervention.

observed 5-months post-intervention

was $45 \%$. Two years post-

intervention, 21 of the 39 children

observed wore helmets.

Hendrickson 391 low income 9- School intervention with parental

Helmet use increased from $18 \%$ to

$\&$ Becker $\quad 10$ year-olds

telephone call to encourage

$55 \% *$ post-intervention. Parent

(1998)

USA

parental reinforcement of bike

involvement correlated with helmet

safety messages.

use post-intervention $(r=-.48 * * *)$ and

1 month later $(r=-.39 * * *)$.

Parkin et al. Two high-income Week long school intervention

Helmet use increased in the high $(4 \%$

and two low-

including parent information

to $36 \% * * *$ ) and low income schools

Canada

income schools and letters and nights.

$(1 \%$ to $7 \% * *)$

18 control schools

(5-14 year-olds)

Schützhofer 78 parents and 124 Theoretical session (50 mins) on

Parental assistance in difficult traffic

et al. (2017)

9-10 year-olds

the development of cycling

situations, intentions to practice 
Austria parents.

competencies and practical

session (50 $\mathrm{min})$ providing

training tips and exercises for cycling with children, self-efficacy

regarding ability to practice cycling

with children, and cycling safety

knowledge significantly increased.

Children performed significantly

better on a practical cycling safety test.

Multiple Road Safety Risks

Childwise 1000 parents of $4-\quad$ Multi-media advertising

$(2008)$

11 year-olds

UK campaign to encourage parents to

set a good example for their

children when on the roads.
Parents were more likely to teach their

children not to cross between parked

cars/to cross where they could see, but

less likely to teach their children to

cross with an adult/to hold hands and

were more likely to engage in unsafe

behaviours (e.g. crossing while talking

on the phone)

Children with Additional Needs

\begin{tabular}{llll}
\hline Phillips \& & 30 10-16 year-olds & 6-month child focused & Children trained by carers had greater \\
Todman & with learning & intervention led by carers or & knowledge $\left(M=723\right.$ vs. $\left.M=669^{* * *}\right)$ \\
$(1999)$ & disabilities & service providers on pedestrian & and pedestrian skill $(M=275$ vs. $M=$ \\
UK & safety. & $\left.236^{* * *}\right)$ than service-led trained \\
& & children post-intervention.
\end{tabular}

1 Note. ${ }^{*} p<.05, * * p<.01, * * * p<.001$. 
